\title{
Autogenous Onlay Graft with Compression Plate for Treatment of Persistent Humeral Shaft Aseptic Non-union with Failed Previous Surgery
}

\author{
Falih Waheed Hashim ${ }^{1}$, Mohammed Baqir Al-Shara ${ }^{2}$, Mohammed Al-Edanni ${ }^{3 * \text { (iD }}$ \\ ${ }^{1}$ Department Orthopedic Surgery, Alzahra Medical Collage, University of Basrah, Basra, Iraq; ${ }^{2}$ Department of Orthopedic \\ Surgery, Wasit Medical Collage, University of Wasit, Wasit, Iraq ${ }^{3}$ Department of Orthopedic Surgery, Al-Kindy Medical Collage, \\ University of Baghdad, Baghdad, Iraq
}

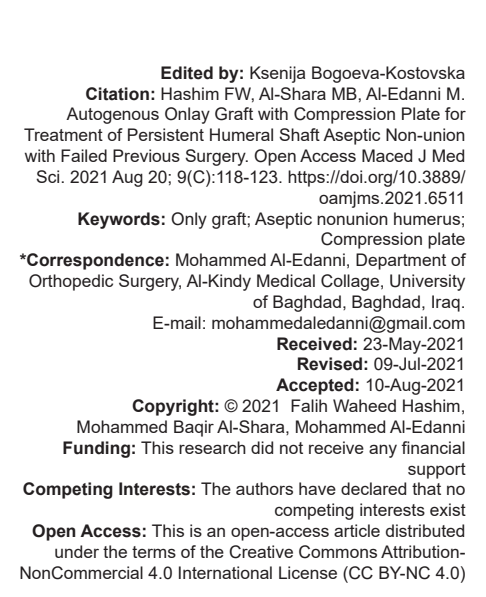

\begin{abstract}
BACKGROUND: The humeral shaft fractures have a good rate of union, despite this fact, still there is a significant rate of nonunion after nonoperative treatment and more often after operative treatment.

AIM: The aim of the study is to evaluate the autogenous onlay graft with compression plate for treatment of persistent humeral shaft non-union with failed previous surgery both radiological and functional outcome.

MATERIALS AND METHODS: A prospective study on twenty patients having persistent aseptic non-union age between 20 and 60 years old, after failed surgical treatment of fractures humeral shaft in Al-Zahra teaching and Al-Kindy teaching hospitals, while infected nonunion, diabetes mellitus, secondary metastasis, smoking, alcoholism, and patients on long medication with corticosteroid were excluded from the study. All our patients were treated with corticocancellous onlay bone grafting harvesting from the ipsilateral upper tibia and compression plating (graft parallel to plate) and follow-up for at least 18 months post-operative to evaluate both radiology and functional using Mayo elbow performance index.
\end{abstract}

RESULTS: All the patients ended with a solid union without hardware failure, and no one patient needs further surgery, even with significant resorption of the graft, there is a good chance of graft re-calcification and solid union with good to excellent functional outcome.

CONCLUSION: Very successful solid union results achieve in those patients with established aseptic nonunion and pseudoarthrosis of the humerus.

\section{Introduction}

Humeral shaft fractures often have a good rate of union whether they are treated operatively, or conservatively with a cast or a brace. About 90 and $95 \%$ of these fractures unite with good functional outcome [1]. Despite a high union rate, still, there is a $1-15 \%$ non-union rate has been reported [2]. Although despite the inherent additional surgery-related risks, the union rate is higher with operative than conservative treatment with fewer reintervention rates [3], [4], [5]. The nonunion is both a radiological and a clinical diagnosis, although the symptoms of fracture become mild or disappear, the fracture does not show a significant signal of healing and there are radiographic pathological changes that indicate cessation of the repair process [6]. The nonunion of the humeral shaft when occurs, it becomes a major therapeutic challenge and it is a difficult problem. There are multiple procedures with different options were recommended in the literature, such as compression plate plus bone grafting, fibular vascularized grafting, and circular external fixation [7]. Still, there is no evidence-based agreement for the ideal treatment option of nonunion of the humeral shaft. Despite the advances in implant technology, plate osteosynthesis remainders the gold standard technique for the operative treatment of humeral shaft fractures and nonunion whether use the conventional open technique or the use of minimally invasive plate osteosynthesis [8]. Atrophic nonunion and pseudoarthrosis is the most difficult type of nonunion to heal and may need multiple operations and osteotomy with wide excision at the fracture site [9].

\section{Materials and Methods}

This is a prospective study that enrolled twenty patients with aseptic non-unions of humeral shaft fractures treated with corticocancellous onlay bone grafting and compression plating, aging between 20 and 60 years old, after failed surgical treatment of fractures 
humeral shaft in Al-Zahra teaching and Al-Kindy teaching hospitals/Iraq, from June 2017 till September 2020 including the follow-up period, while infected nonunion, diabetes mellitus, secondary metastasis, smoking, alcoholism, and patients on long medication with corticosteroid were excluded from the study.

All patients were treated surgically before with fixation and failure to achieve union (Figure 1). Some of them were subjected to more than one operation and no union was achieved. We were managed all the fractures by removal of previous implants, open reduction, and internal fixation with compression plate supplemented by onlay autogenous bone graft (Figure 2) from the upper half of the ipsilateral tibia (Figure 3). The patients were periodically evaluated both clinically and radiologically over 18 months with a follow-up chart.

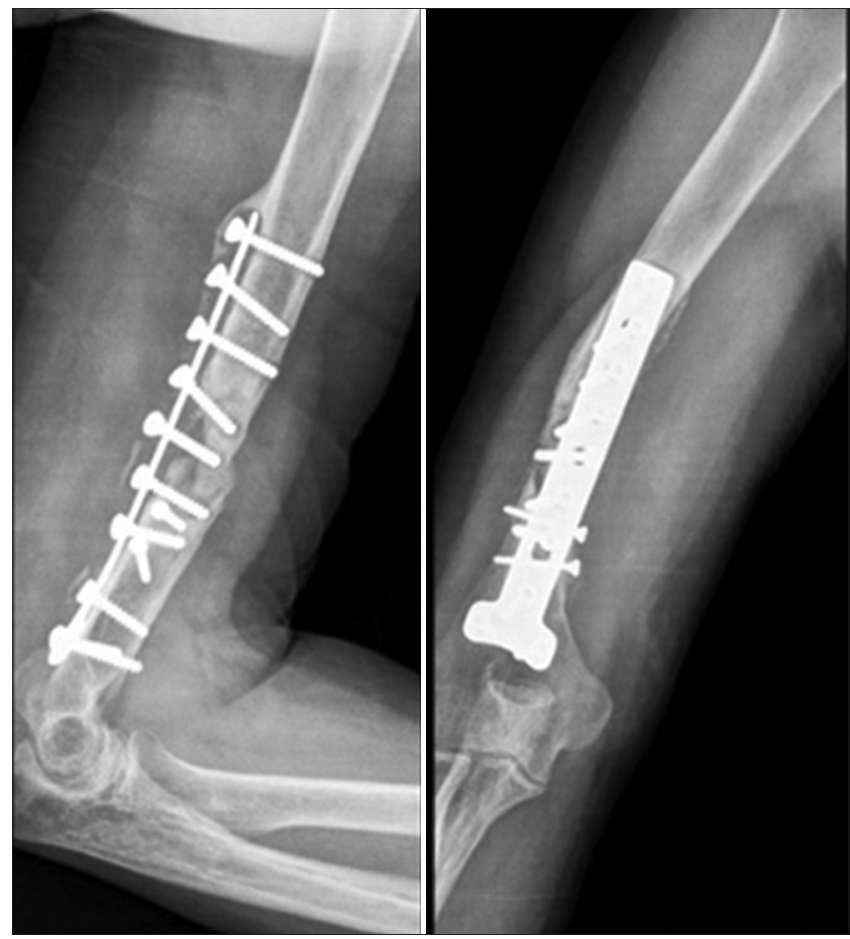

Figure 1: Aseptic nonunion after failed plating humerus

Sixteen patients were surgically treated before by plate and screws with and without additional cancellous bone graft and two cases by external fixation for a compound fracture and two cases were treated by plate and screw, then by nail. Fourteen cases were treated before as acute fractures and six of them were already had nonunion or delayed union after a period of nonoperative treatment with the hanging cast and U-shape plaster then plate and screws augmented by autogenous cancellous bone graft with failure to achieve union.

In this study, all patients were treated by a compression plate and a strut bone graft from ipsilateral tibia fixed rigidly across the fracture site with at least four screws of the plate applied opposite to the graft and pass through the graft to achieve graft fixation and compression against the host bone.

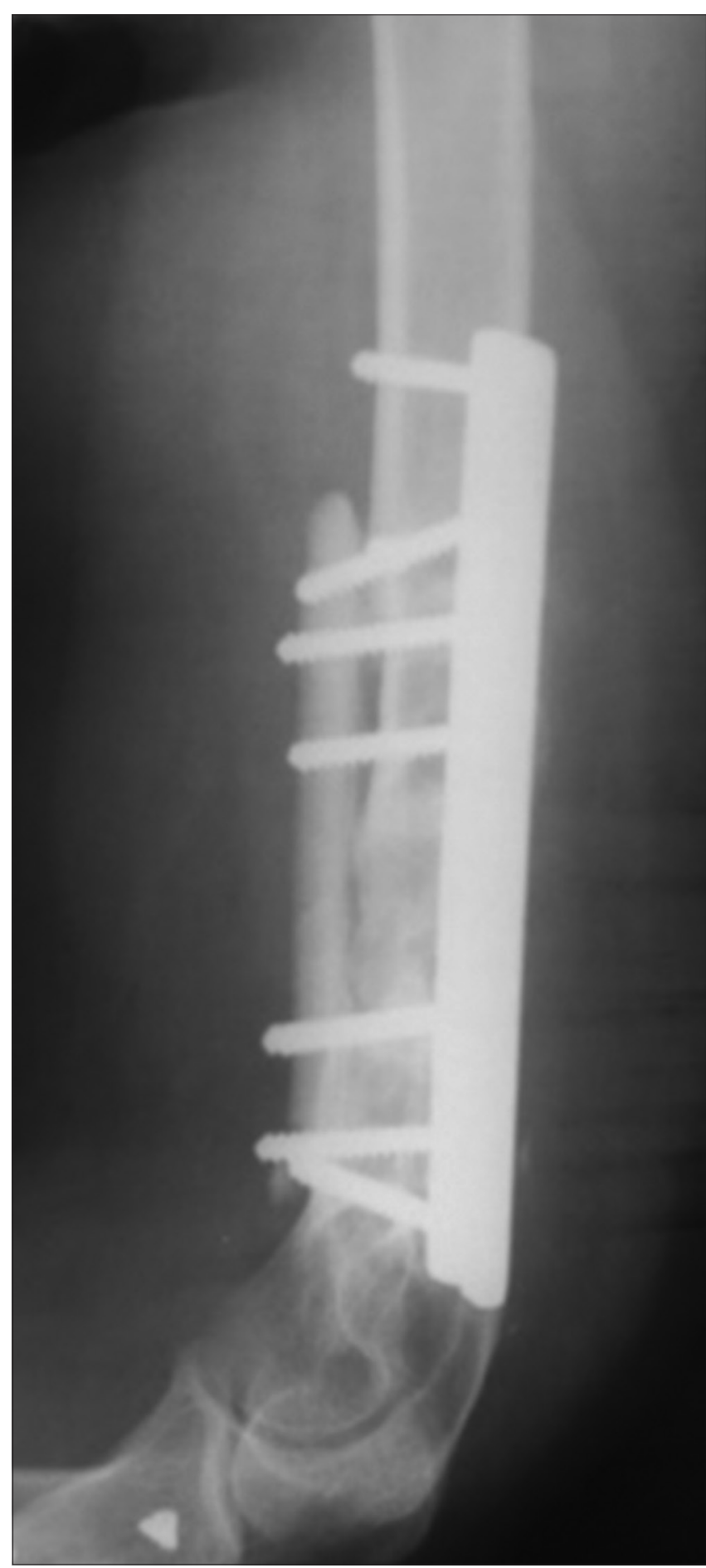

Figure 2: Post-operative fixation by autogenous onlay graft and compression plate

\section{Operative technique}

First of all, we explain the detail of the procedure to the patient and get his consensus on the procedure and the graft. A posterior triceps-splitting approach was chosen. We should take all the precautions to avoid radial nerve injury, the nerve was identified and protected. The old metal was removed. The anterior surface of the humorous was partially decorticated both proximally and distally. A dynamic compression plate was applied to the posterior surface of the humerus 


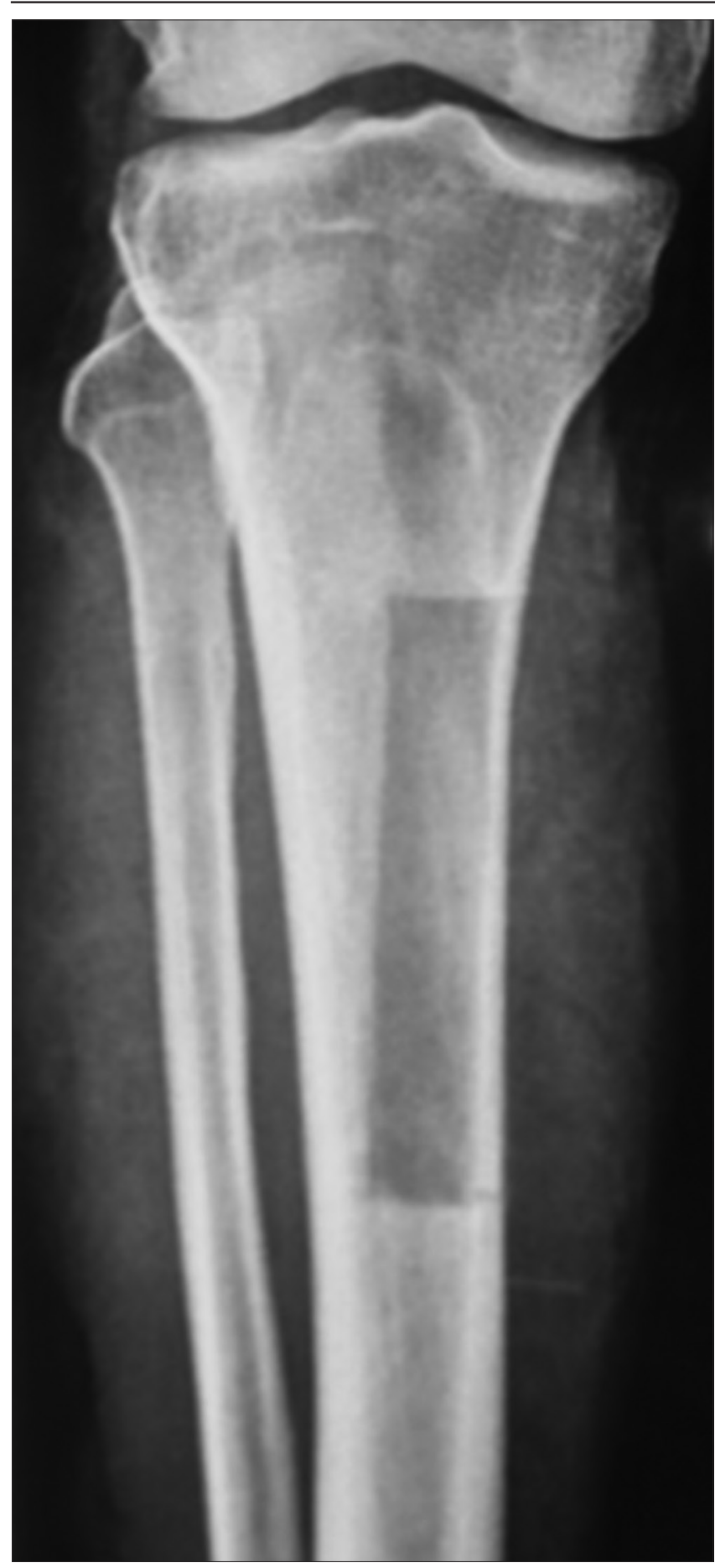

Figure 3: The site of harvested corticocanellous only graft from the upper half of the tibia

with at least four to six points of cortical fixation on both sides of the non-union. It is of critical importance that the compression plate should be applied and fixed before applying the tibial graft. The plate is fixed first by the far distal screws on either side, to obtain a stable well-aligned fracture before the graft application. A one to one and a half centimeter width by $6-8-\mathrm{cm}$ length corticocancellous graft was harvested from the ipsilateral anteromedial tibial surface, and also some strips of cancellous bone were harvested from the donor site. The onlay graft was placed across the non-union site on the anterior aspect of the humorous (parallel to the plate) fixed with at least four screws (two on either side) using the inner holes of the already fixed plate. This will firmly have secured the graft to the humerus. The firm fixation of the graft is important, because the graft in addition to augments the stability of the fracture, also may enhance faster osteogenesis. The remaining chips of the cancellous bone graft were then placed on both the medial and lateral aspects of the fractured site. After good hemostasis and copious normal saline irrigation of the surgical field, the wound then closed routinely [9].

The follow-up period extends to at least 18 months post-operative according to the special chart to evaluated both radiologically and clinically by the Mayo elbow performance index [10] Figure 4.

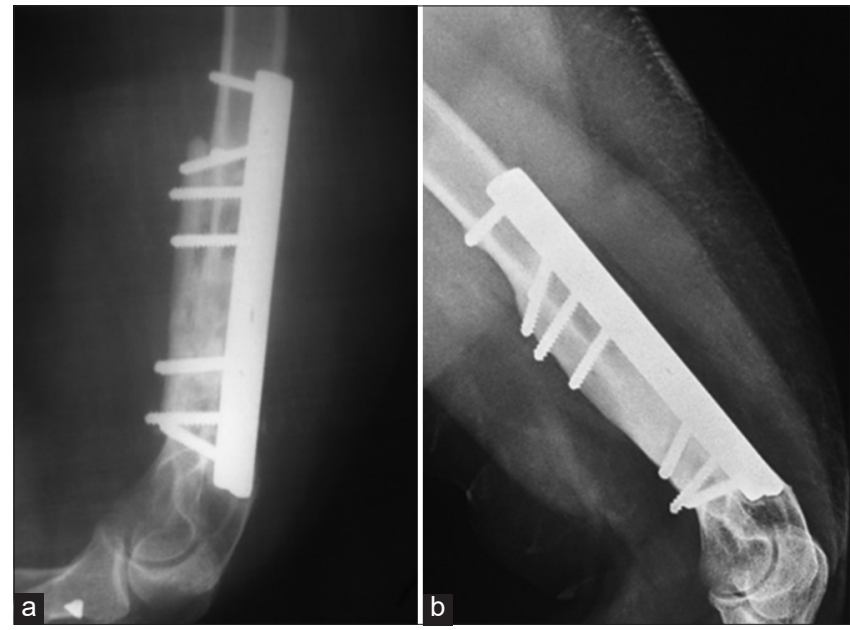

Figure 4: Post-operative follow up a. 6 months, and b. 9 months with solid union

\section{Results}

This study enrolled twenty patients (eight men and twelve women) with previous failed surgical fixation, half of them fixed by plate and screws only, and $30 \%$ with added bone graft to plate (Table 1). Fourteen percent have more than failed surgery (Table 2), The average age of the patients was 38.6 years (range $20-60$ ). The average time from the date of fracture to the date of management of the nonunion was 20.2 months (range 12-36 months). The types of nonunions were atrophic in eight patients, hypertrophic in six patients and synovial pseudoarthrosis was present in six patients, all end with the solid union within 20-28 weeks after the procedure with a good incorporation of the graft. There was no failure of the hardware, and no one

Table 1: Types of previous surgical fixation

\begin{tabular}{lll}
\hline Types of the previous fixation & No. of patients & Percentage \\
\hline Plate and screws & 10 & 50 \\
Plate and screws with bone graft & 6 & 30 \\
External fixation & 2 & 105 \\
Intramedullary nail & 2 & 10 \\
\hline
\end{tabular}


Table 2: Numbers of previous surgical fixation

\begin{tabular}{lll}
\hline No. of previously failed fixation & No. of patients & Percentage \\
\hline One surgery & 12 & 60 \\
Two surgery & 8 & 40 \\
\hline
\end{tabular}

requires further procedures. One patient had a limited range of movement at the elbow, which is probably due to periarticular scarring as a result of the long duration of non-union (3 years) and the presence of a false joint at the fracture site. One patient was complicated by an undisplaced fracture tibia at the donor site due to a fall about 2 months after surgery, it was treated conservatively by plaster of paris and end with the solid union, while temporary radial nerve palsy occurs in two patients $10 \%$ (Table 3 ).

\section{Discussion}

Non-union is a clinical and radiological diagnosis. It is a fracture that shows no substantial sign of healing and reveals radiographic pathological changes with the cessation efforts to repair [11].

Table 3: Complications related to surgery

\begin{tabular}{lll}
\hline Complications & No. of patients & Percentage \\
\hline Temporary radial nerve injury & 2 & 10 \\
Fracture tibia & 1 & 5 \\
Stiff elbow & 11 & 5 \\
\hline \multicolumn{2}{c}{ The underlying causes for non-union of }
\end{tabular}

fracture, in general, are multifactorial and may include elderly patients, diabetes mellitus, obesity, poor nutritional status, alcoholism, chronic liver disease, use of corticosteroids, anticoagulation, radiation therapy, and poor patient compliance [12]. Other factors may be associated with delayed or even nonunion are for example open fractures, transverse fracture pattern especially if treated with a hanging cast which may result in fracture distraction, infections, soft tissue interposition, and insufficient immobilization [13].

Fracture shaft of the humerus when end with non-union, has major orthopedic challenges, and many of those patients with such fracture in efforts to get union are subjected to several operative procedures. currently, the most common surgical options used in treating the humeral shaft non-unions are compression plating with screws fixation and interlocking intramedullary nail fixation [14], [15]. For the treatment of nonunion, historically some authors use compression plating together with methylmethacrylate to achieve stable screw fixation in patients with severe bone osteoporosis [16]. The free vascularized fibular graft is considered by some authors as an efficient technique for aseptic nonunion especially in resistant multi-operated cases particularity those with a bone defect. This procedure is technically demanding and needs excessive dissection [17]. A much lower rate of the union has been reported in those patients with complicated humeral non-unions as those with big bone defect, bad fibrotic soft tissue cover, or advance neuropathic limb [18].

Our patient's average age was 38.6 years and it was lower than the average age obtain in the study of Tzu-Liang et al. 2005 [19] in which average age was 46.2 , also female predominance in our study $60 \%$ and it against the study of Tzu-Liang et al. 2005 [19].

In this study, onlay graft was applied parallel $\left(180^{\circ}\right)$ and opposite to the compression plate and fixed by some of the plate's screws. In some studies [1], [20], they used a long compression plate augmented by a bridging tricoticocancellous onlay bone graft, the graft is applied at an angle of 90 degrees relative to the plate and fixed by separate screws with additional cancellous bone. We achieve $100 \%$ solid union in all patients within 20-28 weeks and it was similar to the study of Annette Billings et al. 1999 [1], Collie et al. 1983 [20], and Tzu-Liang et al. 2005 [19], but higher than the study of Rinne et al. 2015, which achieve $98 \%$ union rate [21]. All of our patients have good to the excellent function of the elbow movement according to Mayo elbow performance index apart from one patient had a fair result at the elbow, which is probably due to periarticular scarring as a result of the long duration of non-union ( 3 years) and the presence of a false joint at the fracture site [7], this similar to result of Tzu-Liang et al. 2005 [19] and Che-Li et al. 2009 [21].

We believe that there are some advantages of the technique used in our study, which increase the chance of union. In addition to achieving good bridging at the nonunion site, it also has another advantage, because the host bone around the fracture site especially the distal segment has a bone loss and/ or has severe osteoporosis which makes poor screws purchase, the strut cortical graft placement opposite to the plate will augment the weak host bone and provide good purchase for the cortical screws of the compression plate which further increases the stability of the construct.

Radial nerve palsies, although temporary, it has been reported in acute fracture surgery and revision surgery of nonunion humeral shaft fracture [21], [22]. It is reported in two cases in our study, in a patient who had nonunion with severe tissue scarring incorporating the nerve, it ends with functional recovery after about 2 months, this similar to study done by Belayneh et al. 2019 [22] and lower than the study of Che-Li et al. 2009 [21], and Tzu-Liang et al. 2005 [19].

Regarding wound infection, two of our patients developed wound infection and were treated with IV antibiotics with complete eradication of infection, and this was similar to the study of Tzu-Liang et al. 2005 [19], and Che-Li et al. 2009 [21].

Interestingly, there is an encouraging result in the present study which is regrowth, and restabilization of the graft after a period of severe graft resorption and 
instability. Clinically, there is a disappearance of pain, tenderness, and crepitus at the fracture site. Also, the X-ray shows signs of onlay graft recalcification. This is probably occurring because of the osteoconduction effect of the graft (bone mineral and collagen), which is just a physical property that permits the graft to serve as a scaffold and permit the ingrowth of neovasculature and infiltration of osteogenic precursor cells into the graft area [23]. Furthermore, other properties of the graft may still be working, as osteoinductivity (bone morphogenetic protein), and osteogenicity (osteoblastic cells, preosteoblastic precursor cells) [24].

We agree with Boldwin et al. 2019 [25], in which the autograft is very osteogenic, easily revascularized, and rapidly incorporate. The rate of vascularization and degree of osteoinduction is the most vital changes between cortical and cancellous grafts, which are less in the cortical one (although it is stronger) due to the dense architecture and lower number of endosteal cells, so it is better to use both, especially in old nonunion with osteoporotic bone fragments. For Osseointegration of the graft to advance successfully, the tissue in the recipient site must have adequate vascularity to diffuse nutrients to the cells before revascularization occurs [26].

We all agree with Salgado et al. 2004 [27], in which the partial decortication of the recipient anterior surface of the humeral shaft is necessary for graft stability as well as to enhance graft osteointegration. The graft incorporation to successfully proceed, it needs adequate vascularity of the host tissue to provide sufficient nutrition for the cells before neovascularization and development of new capillary buds into the graft to produce a vascular network to be more permanent. Furthermore, it has been found that surgically traumatized bone will release cytokines that have osteogenic properties as an insulin-derived growth factor, platelet-derived growth factor, vascular endothelial growth factor, these cytokines will enhance a repair process that leads to the formation of woven bone from the bone surface subjected to the surgical trauma.

\section{Conclusion}

The aseptic nonunion of humeral shaft fracture although it is not common when it does occur it can be difficult to treat. The onlay graft technique from the tibia with compression plate be a very successful procedure that can be used in those patients with aseptic nonunion and previous failed surgical procedure. It can be applied even for patients with true pseudoarthrosis. This technique may be considered as an appropriate alternative to the much more complicated vascularized bone grafting which is much more extensive than the use of non-vascularized onlay graft.

\section{References}

1. Billings A, Coleman SS. Long-term follow-up of the persistent humeral shaft. lowa Orthop J. 1999;19:31-4.

PMid: 10847514

2. Wenzl ME, Porté T, Fuchs $S$, Jürgens $C$. Methods for the reconstruction and osteosynthesis of pseudarthrosis of the humerus. Trauma Berufskrankheit. 2003;5(1):s86-91.

3. van de Wall BJ, Ochen Y, Beeres FJ, Babst R, Link BC, Heng M, et al. Conservative vs. operative treatment for humeral shaft fractures: A meta-analysis and systematic review of randomized clinical trials and observational studies. J Shoulder Elbow Surg. 2020;29(7):1493-504. https://doi.org/10.1016/j.jse.2020.01.072 PMid:32249144

4. Westrick E, Hamilton B, Toogood P, Henley B, Firoozabadi R. Humeral shaft fractures: Results of operative and nonoperative treatment. Int Orthop. 2017;41(2):385-95. https://doi. org/10.1007/s00264-016-3210-7

PMid:27150488

5. Maresca A, Sangiovanni P, Cerbasi S, Politano R, Fantasia R, Commessatti $\mathrm{M}$, et al. Why a surgically treated humeral shaft fracture became a nonunion: A review of 11 years in two trauma centers. Musculoskelet Surg. 2017;101(Suppl 2):105-12. https:// doi.org/10.1007/s12306-017-0509-5

PMid:29052035

6. Panagiotis M. Classification of non-union. Injury. 2005;36(Suppl 4):S30-7.

PMid:16291321

7. Peters RM, Claessen FM, Doornberg JN, Kolovich GP, Diercks RL, van den Bekerom MP. Union rate after operative treatment of humeral shaft nonunion--A systematic review. Injury. 2015;46(12):2314-24. https://doi.org/10.1016/j. injury.2015.09.041

PMid:26499226

8. Kim JW, Oh CW, Byun YS, Kim JJ, Park KC. A prospective randomized study of operative treatment for noncomminuted humeral shaft fractures: conventional open plating versus minimal invasive plate osteosynthesis. J Orthop Trauma. 2015;29(4):18994. https://doi.org/10.1097/bot.0000000000000232 PMid:25210833

9. Babhulkar S, Babhulkar S, Vasudev A. Recalcitrant aseptic atrophic nonunion of the shaft of the humerus after the failure of surgical treatment: Management by excision of nonunion, bone grafting, and stabilization by LCP in different modes. Injury. 2017;48:S33-43. https://doi.org/10.1016/ s0020-1383(17)30492-8

PMid:28802419

10. Longo UG, Franceschi F, Loppini M, Maffulli N, Denaro V. Rating systems for evaluation of the elbow. $\mathrm{Br}$ Med Bull. 2008;87(1):131-61. https://doi.org/10.1093/bmb/ldn023 PMid:18539627

11. Morshed S. Current options for determining fracture union. Adv Med. 2014;2014:708574.

PMid:26556422

12. Nicholson JA, Makaram N, Simpson A, Keating JF. Fracture nonunion in long bones: A literature review of risk factors and surgical management. Injury. 2020;52(Suppl 2):S3-11. https:// doi.org/10.1016/j.injury.2020.11.029

PMid:33221036

13. Olson JJ, Entezari V, Vallier HA. Risk factors for nonunion after traumatic humeral shaft fractures in adults. JSES Int. 2020;4(4):734-8. https://doi.org/10.1016/j.jseint.2020.06.009 PMid:33345208 
14. Rollo G, Prkic A, Bisaccia M, Eygendaal D, Pichierri $P$, Marsilio $A$, et al. Grafting and fixation after aseptic nonunion of the humeral shaft: A case series. J Clin Orthop Trauma. 2020;11(Suppl 1):S51-5. https://doi.org/10.1016/j. jcot.2019.08.020

PMid:31992917

15. Singh AK, Arun GR, Narsaria N, Srivastava A. Treatment of non-union of humerus diaphyseal fractures: A prospective study comparing interlocking nail and locking compression plate. Arch Orthop Trauma Surg. 2014;134(7):947-53. https://doi. org/10.1007/s00402-014-1973-0 PMid:24853958

16. Trotter DH, Dobozi W. Nonunion of the humerus: Rigid fixation, bone grafting, and adjunctive bone cement. Clin Orthop Relat Res. 1986;204:162-8. https://doi. org/10.1097/00003086-198603000-00018 PMid:3514032

17. Kerfant N, Valenti P, Kilinc AS, Falcone MO. Free vascularised fibular graft in multi-operated patients for an aseptic non-union of the humerus with a segmental defect: Surgical technique and results. Orthop Traumatol Surg Res. 2012;98(5):603-7. https:// doi.org/10.1016/j.otsr.2012.03.013

18. Kalra GS, Goel P, Singh PK. Reconstruction of post-traumatic long bone defect with vascularized free fibula: A series of 28 cases. Indian J Plast Surg. 2013;46(3):543-8. https://doi. org/10.4103/0970-0358.122013 PMid:24459347

19. Hsu TL, Chiu FY, Chen CM, Chen TH. Treatment of nonunion of humeral shaft fracture with dynamic compression plate and cancellous bone graft. J Chin Med Assoc. 2005;68(2):73-6. https://doi.org/10.1016/s1726-4901(09)70138-8 PMid:15759818

20. Collie L, Cooney W, Kelly P. Nonunions of the humeral shaft. Orthop Trans. 1983;7:517.
21. Lin CL, Fang CK, Chiu FY, Chen CM, Chen TH. Revision with dynamic compression plate and cancellous bone graft for aseptic nonunion after surgical treatment of humeral shaft fracture. J Trauma Acute Care Surg. 2009;67(6):1393-6. https:// doi.org/10.1097/ta.0b013e31818c1595 PMid:20009693

22. Belayneh R, Lott A, Haglin J, Konda S, Leucht P, Egol K. Final outcomes of radial nerve palsy associated with humeral shaft fracture and nonunion. J Orthop Traumatol. 2019;20(1):18. https://doi.org/10.1186/s10195-019-0526-2 PMid:30923949

23. Kalfas $\mathrm{IH}$. Principles of bone healing. Neurosurg Focus. 2001;10(4):e1.

PMid: 16732625

24. Ansari M. Bone tissue regeneration: Biology, strategies, and interface studies. Prog Biomater. 2019;8(4):223-37. https://doi. org/10.1007/s40204-019-00125-z PMid:31768895

25. Baldwin P, Li DJ, Auston DA, Mir HS, Yoon RS, Koval KJ. Autograft, allograft, and bone graft substitutes clinical evidence and indications for use in the setting of orthopaedic trauma surgery. J Orthop Trauma. 2019;33(4):203-13. https://doi. org/10.1097/bot.0000000000001420 PMid:30633080

26. Roberts TT, Rosenbaum AJ. Bone grafts, bone substitutes, and orthobiologics: The bridge between basic science and clinical advancements in fracture healing. Organogenesis. 2012;8(4):114-24. https://doi.org/10.4161/org.23306 PMid:23247591

27. Salgado AJ, Coutinho OP, Reis RL. Bone tissue engineering: State of the art and future trends. Macromol Biosci. 2004;4(8):743-65. https://doi.org/10.1002/mabi.200400026 PMid:15468269 